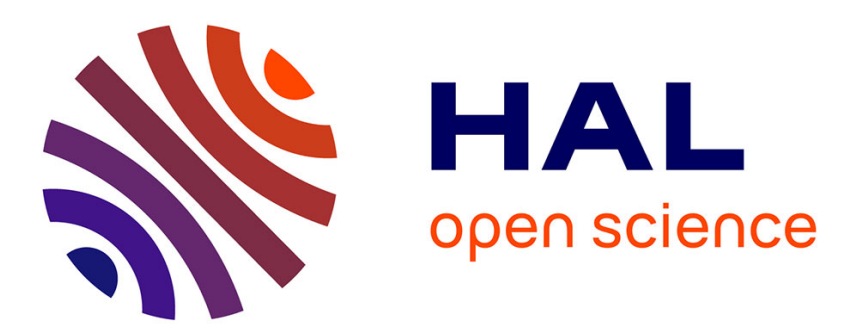

\title{
AN ANALYSIS OF COUNT DATA MODELS FOR THE STUDY OF EXCLUSIVITY IN WINE CONSUMPTION
}

\author{
Víctor Javier Cano-Fernández, Ginés Guirao-Pérez, María Carolina \\ Rodríguez-Donate, Margarita Esther Romero-Rodríguez
}

\section{To cite this version:}

Víctor Javier Cano-Fernández, Ginés Guirao-Pérez, María Carolina Rodríguez-Donate, Margarita Esther Romero-Rodríguez. AN ANALYSIS OF COUNT DATA MODELS FOR THE STUDY OF EXCLUSIVITY IN WINE CONSUMPTION. Applied Economics, 2009, 41 (12), pp.1563-1574. 10.1080/00036840601032227 . hal-00582114

\section{HAL Id: hal-00582114 https://hal.science/hal-00582114}

Submitted on 1 Apr 2011

HAL is a multi-disciplinary open access archive for the deposit and dissemination of scientific research documents, whether they are published or not. The documents may come from teaching and research institutions in France or abroad, or from public or private research centers.
L'archive ouverte pluridisciplinaire HAL, est destinée au dépôt et à la diffusion de documents scientifiques de niveau recherche, publiés ou non, émanant des établissements d'enseignement et de recherche français ou étrangers, des laboratoires publics ou privés. 


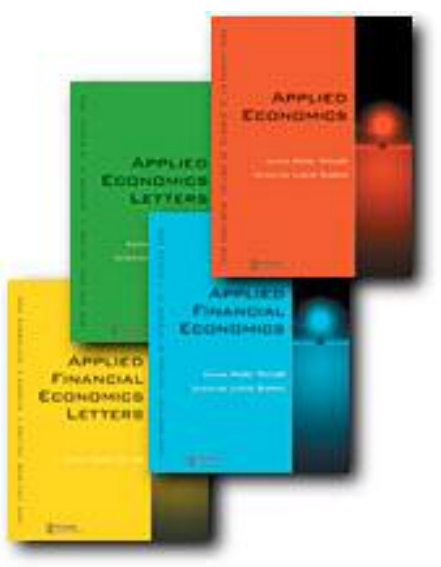

\section{AN ANALYSIS OF COUNT DATA MODELS FOR THE STUDY OF EXCLUSIVITY IN WINE CONSUMPTION}

\begin{tabular}{|c|l|}
\hline Journal: & Applied Economics \\
\hline Manuscript ID: & APE-06-0238.R1 \\
\hline Journal Selection: & Applied Economics \\
\hline JEL Code: & $\begin{array}{l}\text { C25 - Discrete Regression and Qualitative Choice Models }<\text { C2 - } \\
\text { Econometric Methods: Single Equation Models }<\text { C - Mathematical } \\
\text { and Quantitative Methods, Q13 - Agricultural Markets and } \\
\text { Marketing|Cooperatives|Agribusiness }<\text { Q1 - Agriculture }<\text { Q - } \\
\text { Agricultural and Natural Resource Economics }\end{array}$ \\
\hline \hline Keywords: & $\begin{array}{l}\text { Count data models, Poisson regression model, Negative Binomial } \\
\text { regression models, finite mixture models, number of wine types }\end{array}$ \\
\hline
\end{tabular}

\section{S ScholaroNE \\ Manuscript Central}




\title{
AN ANALYSIS OF COUNT DATA MODELS FOR THE STUDY OF EXCLUSIVITY IN WINE CONSUMPTION
}

\author{
Víctor Javier Cano Fernández; Ginés Guirao Pérez; María Carolina Rodríguez \\ Donate y Margarita Esther Romero Rodríguez \\ Departamento de Economía de las Instituciones, Estadística Económica y \\ Econometría \\ Universidad de La Laguna. Campus de Guajara, Camino la Hornera, s/n, 38071, \\ Tenerife, Islas Canarias, España \\ cdonate@ull.es
}

\begin{abstract}
Several models which analyze count data have been proposed in econometric literature. These models allow the discrete, non-negative nature of specific phenomena of interest to be gathered in a appropriate way and can be useful for the explanation of specific preference structures among individuals. In this work, an analysis of the number of wine types consumed by residents of Tenerife is carried out, with an aim to observe which characteristics determine the exclusivity in its consumption, given the current context of increased competition in this sector. The specific characteristics of the considered variable allow the study to cover two aspects. The first is methodological, and is seen by the variety of models that may be considered in this case. This focus consists in comparing several possibilities which fit the type of count data involved. The second aspect is clearly empirical, and is based on the description of not only the most appropriate decision-making mechanism for the study but in the identification of those factors that explain the diversity in wine consumption.
\end{abstract}

Keywords: Count data models, Poisson regression model, Negative Binomial regression models, finite mixture models, number of wine types. 


\section{Introduction}

The worldwide wine scene has gone through significant changes lately, especially since the 90 's. Both producers and wine drinkers have taken turns as the main actors in these changes. The most significant event with respect to demand has been a decrease in worldwide wine consumption, or at least a certain amount of stagnation as a consequence of two opposite effects. On one hand, the increase in demand in countries with traditionally low wine consumption, and the other, a reduction of observed per-capita consumption in those countries where indeed there is greater wine production and tendency to drink wine.

Life style changes have followed a parallel path. For instance, now an increase has been observed in the consumption of higher quality wines than before. Changes have also taken place in traditional family events and social occasions in general, where once daily wine consumption was typical but now has been replaced by an occasional status.

The supply side has also undergone changes. The international players have witnessed the entrance of new countries in a sharing role in two systems of harvesting, production, and commercialization. The first model belongs to the Old World countries and includes France, Italy, Germany, Portugal and Spain. A second type is made up of the New World countries, of which Australia, South Africa, Chile, Argentina and the United States are the major players. As a result there is saturation in the international wine market. The slowdown in demand is accompanied by an increase in the supply of quality wines. And in this environment of increasing competition many wine producers have sensed the need to construct their own image and create a concept of quality that can be perceived by consumers. 
This scenario can even be introduced, with certain overtones, to the Canary Archipelago, and specifically to the island of Tenerife. Vineyards and the wine community arouse analytical interest in this geographical area not only because of its tradition in the wine production process -present in the Archipelago since the 1400 's- but also because of the inherent peculiarity of these wines, namely the climatic conditions, the orography in the island, and the variety of grapes used ${ }^{1}$. Vine growing is also an important asset of undeniable ecological value given its contribution to rural developments, one of the selling points for tourism on the island, which is the true motor of economic activity in the Archipelago.

Increased competition in the wine market, in addition to recent trends defined by consumers, such as the drop in per capita wine consumption and an increase in the demand by consumers for quality wines, have motivated the need for detailed studies regarding consumer behaviour. But these studies need to go beyond such questions as explaining the quantity or frequency of wine consumption, and must include the ways and means in which it is occurring. The characteristics that define the place of consumption or purchase, the origin or region from which the wine came from, and the brand or wine types, can be important when helping develop strategies to sufficiently differentiate wines under current circumstances. Some research indicates that it is difficult to obtain an appropriate economic forecast in the wine sector without a thorough study of demand. Either way it is possible to undertake a study of consumer behaviour using several approaches given the importance that brand loyalty has had in prior research.

This study recognizes the limited amount of available information in this regard. We

\footnotetext{
${ }^{1}$ A significant amount of grape diversity is present in the Canary Archipelago, due to several reasons, one of which is the absence of phylloxera.
} 
therefore choose an approach not based strictly on one dimension but instead adopt a view which will at least allow us to observe consumption behaviour based on exclusivity or diversity. The study specifically aims to describe the socio-economic characteristics which best define the number of different wine types consumed by individuals based on a survey carried out with residents from the island of Tenerife ${ }^{2}$.

In our case a special type of model is necessary to properly gather the characteristics of the phenomenon that is being explained, namely its discrete and non-negative nature. Several alternatives have been proposed in the econometric literature which can fall under the term count data regression models. These models allow us to undertake this type of analysis and also offer some alternatives when defining the structure of consumer preference.

The specific characteristics of this variable allow the study to cover two aspects. The first concerns methodology, which is evident by the variety of models that can be utilized and consists in comparing the alternatives which fit the type of count that is found. The second is eminently empirical, and its goal is to describe not only the most suitable decision making process but to identify which factors explain the increased or decreased diversity in wine consumption.

Given these objectives, the paper is divided into three sections. The first section develops the methodology used, including the different models, noting the most advantageous features of each. Section two describes the data and compares the obtained results from all the models used. The last section draws the most relevant conclusions.

2 Several studies which analyze the influence of socioeconomic characteristics on alcohol consumption are Nayga (1996), Su and Yen (2000) and Selvanathan and Selvanathan (2004). 


\section{Methodology}

\subsection{Standard models for count data}

In our paper the number of wine types is between zero (non consumers) and seven (those wine drinkers, hereafter consumers, who tried all of the wine types considered in the study). A linear regression model is not appropriate for a study of this type since it ignores the special characteristics of this variable and may lead to inefficient, inconsistent and biased estimators.

Models that are traditionally used in the analysis of these types of variables are known as count data regression models. The Poisson regression model is the traditional starting point for count data analysis, where the probability of each count is determined based on a Poisson distribution whose mean, $\lambda_{i}$, is a function of a group of explanatory variables, $x_{i}$, that is,:

$$
\begin{gathered}
P\left(Y_{i}=y_{i} / x_{i}\right)=\frac{e^{-\lambda_{i}} \lambda_{i}^{y_{i}}}{y_{i} !}, \quad y_{i}=0,1,2, \ldots \\
\lambda_{i}=E\left[y_{i} / x_{i}\right]=\exp \left(x_{i}^{\prime} \beta\right)^{3} .
\end{gathered}
$$

Explanatory variables of the model collect the observed heterogeneity, since they are the only source which can be differentiated among the individual ones. The distinct observed values from the explanatory variables lead to different $\lambda$ values, while all the individual ones with the same value of the explanatory variables produce the same value of $\lambda$.

The equality of the conditional mean and variance in the Poisson model is one of its main characteristics and reflects its heteroskedastic nature. Nevertheless, it is also

\footnotetext{
${ }^{3}$ Note that the log-linear formulation of the parameter $\lambda_{i}$ ensures the positive nature of the mean of the dependent variable.
} 
one its primary disadvantages, namely its inability to capture potential overdispersion $^{4}$ which tends to be present in most data.

The search for greater flexibility has led to the introduction of other models, some of which are also based on the Poisson distribution. These models are better at capturing the overdispersion and other characteristics, such as the excess of zeroes or the existence of long tails on the right side (of the distribution), which are considered as signs of unobserved heterogeneity ${ }^{5}$ (Mullahy, 1997).

This unobserved heterogeneity is generally accounted for by introducing a multiplicative error term, $v_{i}$, in the conditional mean of the Poisson model, generating a new group of models, continuous mixture models, whose mean is a random variable:

$$
\lambda_{i}^{*}=E\left[y_{i} / x_{i}, v_{i}\right]=\lambda_{i} v_{i}=e^{x_{i}^{\prime} \beta} e^{\varepsilon_{i}}
$$

One of these models is the negative binomial model ${ }^{6}$. Its representation as a Poissongamma mixture model is obtained by assuming that the unobserved heterogeneity term $^{7}, v_{i}$, distributed as gamma $(\Gamma(\delta, \delta))$ with $\sigma_{v_{i}}^{2}=1 / \delta \equiv \alpha$ (dispersion parameter) and $E\left[v_{i}\right]=1$, which leads to the negative binomial probability density ${ }^{8}$ :

$$
P\left(Y_{i}=y_{i} / x_{i}\right)=\frac{\Gamma\left(\alpha^{-1}+y_{i}\right)}{\Gamma\left(\alpha^{-1}\right) \Gamma\left(y_{i}+1\right)}\left(\frac{\alpha^{-1}}{\alpha^{-1}+\lambda_{i}}\right)^{\alpha^{-1}}\left(\frac{\lambda_{i}}{\alpha^{-1}+\lambda_{i}}\right)^{y_{i}}
$$

with mean and variance defined as:

\footnotetext{
${ }_{5}^{4}$ Overdispersion means that the conditional variance is greater than the conditional mean.

${ }^{5}$ The problem of unobserved heterogeneity occurs in application in which behavioural differences among individuals can not properly "captured" by the group of explanatory variables in the conditional mean function of the model.

${ }_{7}^{6}$ This type of model can also be inspired by different approaches. See Boswell and Patil (1970).

7 This term can pick up a specification error, such as the omission of some explanatory variable (Gourieroux et al, 1984a, b) or by the intrinsic random process (Hausmann et al, 1984).

${ }^{8}$ This probability function refers specifically to the NEGBIN II model.
} 


$$
\begin{aligned}
& E\left[y_{i} / x_{i}\right]=\lambda_{i}, \\
& V\left[y_{i} / x_{i}\right]=\lambda_{i}\left(1+\alpha \lambda_{i}\right) .
\end{aligned}
$$

Cameron and Trivedi (1986) propose a more general model, the NEGBIN k with variance $V\left[y_{i} / x_{i}\right]=\lambda_{i}+\alpha \lambda_{i}^{2-k}$. If $k=0$, the resultant model is the NEGBIN II. In the case where $k=1$ we have the NEGBIN I model.

These standard proposed models face two types of major limitations. The first limitation assumes a zero and positive observations are generated by the same data process. This is the case that we are analyzing, assuming the same preference structure for consumers and non-consumers. A second limitation is characterized by its rigid structure considering its unobserved heterogeneity and is based on known parametric distributions. Therefore it is useful to consider other models that offer greater flexibility regarding these issues.

\subsection{Hurdle models}

Hurdle models, also known as two parts models, are typical alternatives and have been used in a number of applications. These models were developed by Cragg (1971) for continuous data in the Tobit model context. Nevertheless they are quite useful in data count analysis if we observe a number with many zeros and even cases where there are hardly any zeroes at all when compared to the Poisson model (Winkelmann and Zimmermann, 1995) ${ }^{9}$.

\footnotetext{
${ }^{9}$ The data base in this study reveals that the number of zeros represents an important percentage $(24 \%)$ of all observations.
} 
Early work with this class of count data models are described in Johnson and Kotz (1969). Nevertheless not until Mullahy (1986) were economic applications seen and regression effects explained ${ }^{10}$.

The consideration of the individual decision making process is one of the principal characteristics of these models. In the first stage (hurdle part), the individual decides, for example, if he wants to consume a product or not, and in the second stage (called the parent-process), given an affirmative decision, he decides how much he wants to consume. As a consequence of this decision, the probability of a zero response is modelled separately of the probability of a positive result, that is:

$$
\begin{aligned}
& P(Y=0)=f_{1}(0) \\
& P(Y=y)=f_{2}(y) \frac{1-f_{1}(0)}{1-f_{2}(0)}=\phi f_{2}(y), \quad y=1,2, \ldots
\end{aligned}
$$

where $f_{1}(\cdot)$ and $f_{2}(\cdot)$ are probability density functions which may or may not be the same type, $f_{1}$ governs the hurdle part and $f_{2}$ the process once the hurdle has been passed. These models can be seen as a finite mixture compared to the Negative Binomial, which assumes a combination of continuous random variables, due to the combination of the zeros generated by a distribution and the positive values generated by a truncated distribution (Cameron and Trivedi, 1998).

Mullahy (1986) offered two Poisson distributions with parameters $\lambda_{1}=e^{x_{i}^{\prime} \beta_{1}}$ and $\lambda_{2}=e^{x_{i}^{\prime} \beta_{2}}$ for $f_{1}($.$) and f_{2}(\cdot)$, respectively ${ }^{11}$, leading to the Hurdle Poisson model,

\footnotetext{
${ }^{10}$ Yen (1999) compares continuous and count data hurdle models to study cigarettes consumption by women in the US finding similar demand elasticities with respect to continuous explicative variables. ${ }^{11}$ Although in this case the set of explanatory variables is the same, it is possible that it can differ.
} 
which converts into the standard Poisson model if both groups of parameters coincide $^{12}$ :

$$
\begin{aligned}
& P\left(y_{i}=0\right)=e^{-\lambda_{1, i}} \\
& P\left(y_{i}=j\right)=\frac{\left(1-e^{-\lambda_{1, i}}\right) e^{-\lambda_{2, i}} \lambda_{2, i}^{j}}{j !\left(1-e^{-\lambda_{2, i}}\right)}, \quad j=1,2, \ldots
\end{aligned}
$$

The estimation of the parameters for maximum likelihood on this type of models can be carried out through separate optimization of both components, namely the binary process and the truncated one. On many occasions, the first part is represented by a logit or probit model. As pointed out by Deb and Trivedi (2002), this choice does not have significant effects on the estimated probabilities.

\subsection{Finite mixture models}

The previous models can be seen as belonging to the finite mixture class, as indicated earlier, although they also assume certain restrictions which can be overcome. These restrictions include a sample that is divided into two subsets representing zero and positive observations, which can be generated by different processes and represent a special case of the finite mixture which incorporates a degenerate component. An alternative to this proposal is seen in the construction of finite mixture models which belong to family of latent class models (Lindsay, 1995). These models show greater flexibility and other important advantages which allow for a combination of zero and positive values. Finite mixture models have been extensively used in statistics, but only recently have they achieved recognition due to their applications in various areas of research (Leisch, 2004).

\footnotetext{
${ }^{12}$ Other authors have used different versions of this model, such as the negative binomial (Gurmu and Trivedi, 1996).
} 
The random variable in this type of model is assumed to be taken from a population which is an additive mixture of $C$ distinct subpopulations in proportions $\pi_{1}, \ldots, \pi_{C}$, where:

$$
\sum_{j=1}^{C} \pi_{j}=1, \quad \pi_{j} \geq 0, \quad j=1, \ldots, C
$$

The mixed density function is then expressed by:

$$
f\left(y_{i} / \theta\right)=\sum_{j=1}^{C} \pi_{j} f\left(y_{i} / \theta_{j}\right) \quad i=1, \ldots, n
$$

where $f\left(y_{i} / \theta_{j}\right)$ is the density function of each subpopulation $j, j=1,2,3, \ldots, C$.

These distributions can belong to different parametric families, although normally it is assumed that they belong to the same one (for example, Poisson, Negative Binomial, etc). In general, the $\pi_{j}$ are unknown parameters that must be jointly estimated with the rest of the parameters from the model, $\theta$, with $\pi_{C}=1-\sum_{j=1}^{C-1} \pi_{j}$.

These $\pi_{j}$ can be parameterized as a function of a group of explanatory variables, using a logit function (see, for example Wang et al, 1998), however identification problems can arise, hence in many cases these are estimated as simple constants (Deb and Trivedi, 1997, among others).

Finite mixture models offer a natural and intuitively attractive representation of the heterogeneity in a finite number of usually small, latent classes, where each one of which can be considered as a type or a group. The choice of the number of components of the mixture determines the number of types. If these components have a natural interpretation, then a characterization of the finite mixture is 
interesting, however, this is not essential since the finite mixture can be simply expressed in a flexible and parsimonious way of modelling the data (Cameron and Trivedi, 1998).

\subsection{Models for a subsample}

In some instances, the range of the dependent variable is partially observable or only one subset of the population is of interest because it represents specific type of behaviour. For example, only those individuals who have tried at least a certain number of wine types are considered. This context reveals a truncated sample towards the left, typically with the truncation at zero, and in our case, only consumers.

The standard way of gathering this type of behaviour involves the use of Poisson or truncated Negative Binomial models ${ }^{13}$. These models coincide with the second part of the hurdle model discussed earlier. This case is characterized by the assumption that the behaviour of the dependent variable follows some of these distributions and that the observed counts are restricted to positive values.

An alternative way to deal with the truncation at zero is by changing the sample space. This approach is different then the one obtained by the conditional distribution, and the probability function would be given by:

$$
P\left(Y_{i}=y_{i} / x_{i}\right)=\frac{e^{-\lambda_{i i}} \lambda_{i}^{y_{i}-1}}{\left(y_{i}-1\right) !}, \quad y_{i}=1,2,3 \ldots
$$

where now

\footnotetext{
13 Gurmu (1991), Grogger and Carson (1991), Gurmu and Trivedi (1992), among others, have commented on these models. Recent application in order to look for some evidence of the presence of reputation in the return to tourist destination can be found in Ledesma et al (2005).
} 


$$
\begin{aligned}
& E\left[y_{i} / x_{i}\right]=\lambda_{i}+1 \\
& V\left[y_{i} / x_{i}\right]=\lambda_{i}
\end{aligned}
$$

This distribution is known as the Displaced Poisson (Jonson and Kotz, 1969) and agrees with the one obtained by Shaw (1988) for the treatment of on-site sampling ${ }^{14}$. Although the basis for the truncated distribution and the one obtained from this last distribution is the same, both are different (Cameron and Trivedi, 1998, p. 331).

Finally, our approach can be extended to the different versions of the Negative Binomial and the finite mixture model which were presented in previous sections. The finite mixture model only requires an explanation of how new obtained distributions for the different classes are going to be considered. The optimization procedure follows the same steps as in the original.

\section{Data and Results}

\subsection{Data}

The data used in this study came from an exhaustive survey regarding wine consumption in Tenerife which took place during April and May, 2001. The survey included questions related to residents' drinking habits and preferences with respect to wine consumption in general and specifically wine from Tenerife ${ }^{15}$. The variables that were used in our analysis include the type of wine consumed, the frequency of consumption and others of a socioeconomic nature. A description is included in table 1 of the appendix.

We thought it would be important to put together a descriptive analysis of the number of wine types. This analysis would give us an initial idea about the

\footnotetext{
${ }^{14}$ See Englin and Shonkwiler (1995) for an extension to the Negative Binomial.

${ }^{15}$ See Guirao et al (2001) for a detailed description of the survey.
} 
diversification of wine consumption. Some significant results obtained from the contingency tables between this variable and the frequency of consumption are discussed. Comparisons with other socioeconomic variables were also performed.

Our first observation is that the majority of individuals who drink wine tend to choose between one and three different types. Specifically $35.73 \%$ of all individuals tend to drink two different wine types. These two wine type combinations are local bottled wine with Apellation d' Origin (A.O.) and imported wine with A.O (29.2\%). The next group includes local table wine and local bottled wine with A.O (25.8\%). When considering those individuals who drink just one type of wine $(27.64 \%)$, the most common type was local table wine (35.8\%), local bottled wine with A.O. (33.7\%), imported bottled wine with A.O. (16.3\%) and self produced local table wine (12.6\%). In addition, $20.67 \%$ drink three different types of wines. The most common combination among this three type group was imported table wine, local bottled wine with A.O. and imported bottled with A.O., representing 38\%.

Table 1. Frequency Distribution: number of wine types

\begin{tabular}{|c|c|c|c|}
\hline $\begin{array}{l}\text { Number } \\
\text { of types }\end{array}$ & Frequency & $\begin{array}{c}\text { Overall } \\
\text { \% }\end{array}$ & $\begin{array}{c}\text { \% of those that } \\
\text { consumer }\end{array}$ \\
\hline 0 & 282 & 24.06 & ------ \\
\hline 1 & 246 & 20.99 & 27.64 \\
\hline 2 & 318 & 27.13 & 35.73 \\
\hline 3 & 184 & 15.70 & 20.67 \\
\hline 4 & 73 & 6.23 & 8.20 \\
\hline 5 & 33 & 2.82 & 3.71 \\
\hline 6 & 26 & 2.22 & 2.92 \\
\hline 7 & 10 & 0.85 & 1.13 \\
\hline
\end{tabular}

On the other hand we note from the contingency tables that on average, males consume $25 \%$ more wine types than females. In addition, the average number of wine types consumed in the first four age categories is practically the same and is nearly 2, while this average drops to 1.5 for the 60 to 69 age group, before settling 
down to 1.0 after age 70 . Regarding residence, the southern and metropolitan areas consume a greater variety of wines, especially among singles and married individuals. This variety is also greater among professionals, businessmen and civil servants, while housewives consume a smaller amount of wine types. An increase in income corresponds to an increase in the variety of wines consumed, although this is not the case for specific levels of education. For instance, university students and those individuals with primary school studies are those that consume the greatest amount of distinct wine types. Regarding consumption frequency we observe that, in general, as the frequency in wine consumption increases, so does the average number of wine types consumed. Specifically, those who seldom drink will consume on average approximately 2 different types of wine, while this figure rises to 2.5 for those who drink occasionally and 2.8 for those who drink often. Finally the average number of wine types for those who drink daily is 2.5 , although the dispersion of these with respect to the average number of wine types is the highest of all the categories.

This relation among the number of wine types and consumption frequency suggests that frequency, along with other socioeconomic characteristics, can be a determining factor in the variety of wine types that the individual consumes and is the reason why it is included as an explanatory variable in the models used in the study.

\subsection{Results}

Several models have been tested for all individuals and for the sub-sample of consumers with the aim of analyzing the role of exclusivity in the consumption of wine. Both cases initially used the Negative Binomial and Poisson models. Two assumptions are made with respect to the Negative Binomial: one, that the variance is considered to be proportional to the mean, leading to the NEGBIN I model, and 
two, that the variance is defined as a quadratic function of the mean, resulting in the NEGBIN II model.

Both NEGBIN I and NEGBIN II models reveal that the parameter of dispersion $(\alpha)$ is not significant for the sample. This result suggests that the overdispersion present in the data is not very high (see table 2 in the appendix), which is reasonable given the relative nearness that exists between the mean and variance of the dependent variable, 1.8063 and 2.365 , respectively.

In order to compare the Poisson model with the negative binomial approximations we began with the optimal regression-based test proposed by Cameron and Trivedi (1990) to check for overdispersion or underdispersion in the Poisson model ${ }^{16}$. This test is based on the OLS auxilliary regression between $z_{i}=\left\lfloor\left(y_{i}-\mu_{i}\right)^{2}-y_{i}\right\rfloor \sqrt{2} \mu_{i}$ and $w_{i}=g\left(\mu_{i}\right) / \sqrt{2} \mu_{i}$, where $g\left(\mu_{i}\right)$ is equal to $\mu$ or $\mu_{i}^{2}$ and in the posterior significance testing of the coefficient. In both cases, this coefficient is practically null and not significant, indicating scarce presence or absence of overdispersion in the data. We then use the common LR (likelihood ratios) ${ }^{17}$ to compare nested models. In this case no evidence is found to reject the Poisson model against the NEGBIN I and II models ${ }^{18}$.

${ }_{16}\left\{\begin{array}{l}H_{0}: \operatorname{var}\left(y_{i}\right)=\mu_{i} \\ H_{1}: \operatorname{var}\left(y_{i}\right)=\mu_{i}+\alpha g\left(\mu_{i}\right)\end{array}\right.$
${ }^{17} L R=-2\left(\operatorname{Ln} L_{0}-\operatorname{Ln} L_{1}\right) \sim \chi_{q}^{2}$, where $L_{0}$ is the likelihood function for the restricted model and $L_{1}$ for the unrestricted model.

${ }^{18}$ We previously studied the influence of certain socioeconomic characteristics of the individual on the number of wine types that are being consumed, but without considering the effect of consumption frequency. In this paper the Poisson model was rejected against the two negative binomial estimates using traditional overdispersion tests. This result leads us to consider whether the differences among individuals are not only due to observed heterogeneity but also to unobserved heterogeneity. The unobserved heterogeneity term included in the conditional mean of the negative binomial models can capture the effect of one explanatory variable which has been omitted in the model. The current study includes consumption frequency as the explanatory variable and has not lead to the rejection of the Poisson model against the two negative binomial models. Consequently we can consider that this 
A Hurdle Poisson model (HPM) and Finite Mixture Poisson Model (FMPM) (see table 2 in appendix) are also included with the prior estimates. The Hurdle model separately models the probability of individual decision to not drink from the one where he decides to drink a specific number of wine types, while the finite mixture model considers two components (latent classes) that could initially be interpreted in relation to the level of exclusivity in the consumption. The dichotomy between these two groups would be characterized by a mean and variance of the number of wine types consumed where the first model has a lower value than the second. In our study the means are, respectively, 1,70 and 2,55, with variances of 0.974 and 6.15 . Similarly the significance of $\pi_{j}$ confirms the hypothesis of the two subpopulations, whose estimated proportions would be 0.847 and 0.153 .

Given that the Hurdle Poisson model and the FMPM models are not nested, two standard choice criteria are used in the comparison, namely the Akaike Information Criteria (AIC) and the Bayesian Information Criteria (BIC) ${ }^{19}$.

Table 2. Model selection (Information Criteria)

\begin{tabular}{|c|c|c|c|c|}
\hline & Criteria/Model & Poisson & $\begin{array}{c}\text { Hurdle } \\
\text { Poisson } \\
\text { model }\end{array}$ & $\begin{array}{c}\text { Finite } \\
\text { mixture } \\
\text { Poisson } \\
\text { model }\end{array}$ \\
\hline \multirow{2}{*}{$\begin{array}{c}\text { Total Sample } \\
(\mathbf{N}=\mathbf{1 1 7 2})\end{array}$} & AIC & 3547.2 & 3857.7 & 3535.4 \\
\hline \multirow{2}{*}{$\begin{array}{c}\text { Consumer } \\
(\mathbf{N}=\mathbf{8 9 0})\end{array}$} & BIC & 3704.9 & 4167.1 & 3848.3 \\
\cline { 2 - 5 } & AIC & 2701,9 & --- & 2665,3 \\
\hline
\end{tabular}

Based on the results from the prior table we conclude that the Hurdle Poisson model should be rejected in favour of the other alternatives, where the Finite Mixture

variable has assisted in explaining the individual differences that were initially attributed to unobserved heterogeneity, and specifically, to overdispersión.

${ }^{19} \mathrm{AIC}=-2 \ln \mathrm{L}+\mathrm{k} ; \mathrm{BIC}=-2 \ln \mathrm{L}+\mathrm{k} \ln (\mathrm{N})$, where $L$ is the maximum likelihood function, $k$ is the number of parameters that are estimated and $N$ is the number of total sample observations. 
Poisson Model is preferred according to the AIC and the Poisson model is favoured by the BIC.

The nested models allow us to compare using likelihood ratio tests. In this case the statistic takes on a value of 39.766 which, at the $5 \%$ significance level, leads to the rejection of the Poisson model in favour of the latent class model. Fitted relative frequencies were calculated for each model, considering the entire sample or only consumers. For the first case (see table 3) our review reveals that all of the models under study tend to underestimate the number of zeros and overestimate the number of ones. Nevertheless good behaviour is observed when counts are greater than or equal to two. Most of the models adequately capture each one of the counts when only considering consumers (see table 4). In this situation the finite mixture model stands out.

Table 3.

Actual and fitted distributions: (Relative frequencies for different models) $\mathrm{N}=1172$

\begin{tabular}{|c|c|c|c|c|}
\hline $\begin{array}{l}\text { Number } \\
\text { of types }\end{array}$ & Observed & Poisson & Hurdle Model & Finite Mixture \\
\hline 0 & 0.24 & 0.16 & 0.15 & 0.16 \\
\hline 1 & 0.21 & 0.30 & 0.28 & 0.29 \\
\hline 2 & 0.27 & 0.27 & 0.27 & 0.27 \\
\hline 3 & 0.16 & 0.16 & 0.17 & 0.16 \\
\hline 4 & 0.06 & 0.07 & 0.08 & 0.07 \\
\hline 5 & 0.03 & 0.03 & 0.03 & 0.03 \\
\hline 6 & 0.02 & 0.01 & 0.01 & 0.01 \\
\hline 7 & 0.01 & 0.00 & 0.00 & 0.00 \\
\hline
\end{tabular}

Table 4.

Actual and fitted distributions: (Relative frequencies for different models) $\boldsymbol{N}=890$

\begin{tabular}{|c|c|c|c|c|}
\hline $\begin{array}{l}\text { Number } \\
\text { of types }\end{array}$ & Observed & Poisson & $\begin{array}{c}\text { Truncated } \\
\text { Poisson }\end{array}$ & Finite Mixture \\
\hline 1 & 0.28 & 0.25 & 0.33 & 0.29 \\
\hline
\end{tabular}




\begin{tabular}{|l|l|l|l|l|}
2 & 0.36 & 0.35 & 0.32 & 0.36 \\
\hline 3 & 0.21 & 0.24 & 0.20 & 0.22 \\
\hline 4 & 0.08 & 0.11 & 0.10 & 0.09 \\
\hline 5 & 0.03 & 0.04 & 0.04 & 0.03 \\
\hline 6 & 0.03 & 0.01 & 0.01 & 0.01 \\
\hline 7 & 0.01 & 0.00 & 0.00 & 0.00 \\
\hline
\end{tabular}

Age generally influences the number of wine types chosen by the consumer. This finding is consistent with the Finite Mixture Poisson Model (FMPM). As a result the number of variety of wine consumed decreases as the individual gets older. This characteristic is also present in the rest of the models. Other determining factors in the rest of the models are geographical area and consumption frequency. There is a wide range among consumption in the southern part of the island, and especially in the metropolitan area, when compared to the northern part of the island. Nonetheless, its influence in the finite mixture model is different for both considered classes. For instance, a significant impact is noted in the southern area for the group of less exclusive wine drinkers, and for the metropolitan area, it is the most exclusive. Consumption frequency has a similar effect on both collected classes in the finite mixture model. This fact can be interpreted as non discriminatory among the obtained groups.

The income variable does not affect the number of wine types except in the Finite Mixture Model, although it is noteworthy that this variable is only significant in the second group of individuals. In this case its effect is negative, displaying greater exclusivity with income level. Similarly, occupation can also capture the effect of income, and is also only significant for this part of the model in some categories (businessmen, professionals and others), where its effect is positive. It is worth noting the sex variable is not an explanatory factor in any of the models, although it is interesting that a high correlation exists between the sex variable and the frequency 
of consumption, which is significant. Education level, in general, is not significant, as seen by individuals with university studies who show the greatest variability in our sample.

With regard to the subsample of wine drinkers, we followed the procedure described in section 2.4. As observed in Table 2, the obtained results for the choice of models are the same as those for the complete sample. That is, according to the AIC criteria the FMPM is preferred, while the BIC criteria points to the Poisson model. The statistical value of the likelihood ratio test among these nested models is 64.64, rejecting the Poisson model against the Finite Mixture Model at the 5\% significance level. The proportions for each class are significant for the Finite Mixture Model, estimated at 0.758 and 0.242 , respectively. As we mentioned earlier, this can be an indication of the presence of two subpopulations that show a different response with respect to the greater or lesser exclusivity in consumption.

The obtained results are, in some aspects, similar to those obtained for the entire sample (see table 3 in the appendix). That is, for the standard Poisson model, age, geographical location and consumption frequency are seen as relevant factors, but not educational level. The greatest variability is found in the set of individuals with university studies. This last result is also generated by both groups in the finite mixture model. Occupation is also not relevant in this model for the least exclusive group. Note, however, that income has a positive effect in the most exclusives, even when the negative impact for the first group is obtained. Finally the remaining factors, which include age, geographical area and consumption frequency, reveal similar behaviour to that obtained from our entire sample, although in this case the impact of consumption frequency is lesser for both groups. 


\section{Conclusion}

In this study several approaches regarding the analysis of wine type consumption by the residents in Tenerife have been presented. Standard approximations (Poisson, NEGBIN I and NEGBIN II) have been compared with more flexible ones (Hurdle Poisson Model and the Finite Mixture Poisson Model with two components). These last two have been proposed as alternatives in the data count context which normally shows relatively high means and long tails, thus producing greater advantages than those found in typical parametric versions (Guo and Trivedi, (2002)). In our case, the count type showed different characteristics than those mentioned, and motivated the interest in exploring these alternatives from an empirical point of view.

Based on some traditionally used criteria in model selection for count data it can be concluded that Negative Binomial models are not superior to the Poisson model. A comparison of the Poisson model with the other two models which do not assume the same preference structure for consumers and non-consumers (Hurdle Poisson Models), or those that assume the presence of subpopulations with different response (Finite Mixture Poisson Model) is carried out. In our study the Poisson model or the Finite Mixture Poisson Model is chosen according to the criteria utilized. Nevertheless our results indicate that these models can be, marginally at least, more appropriate when including this particular type of count. At any rate other semiparametric and non-parametric alternatives are open to further research in this area.

A summary of the results obtained from our study regarding the determining factors based on the level of exclusivity in the consumption of wine shows that, in general, the age of the individual —where a smaller variety of wine types remain as individuals age-, the individuals residence - in this case the most exclusive consumption occurs in the northern part of the island - and drinking frequency are 
the most relevant factors. In addition income and education are exceptionally relevant for certain models. These factors also show behaviour patterns which are differentiated according to the group of individuals considered in the Finite Mixture Poisson Model, providing this model perhaps with a more realistic and useful approach to represent the heterogeneity of the observed phenomena.

\section{References}

BOSWELL, M.T. and PATIL, G.P. (1970): "Chance Mechanisms Generating the Negative Binomial Distributions", in Patil, G.P., Random Counts in Models and Structures, vol. 1-3, University Park, PA, and London, Pennsylvania State University Press.

CAMERON, A.C. and TRIVEDI, P.K. (1990): "Regression-based Tests for overdispersion in the Poisson Model", Journal of Econometrics, 46, 347-364.

CAMERON, A.C. and TRIVEDI, P.K. (1998): "Regression Analysis of Count Data", Cambridge University Press.

CRAGG, J.C. (1971): "Some Statistical Models for Limited Dependent Variables with Application to the Demand for Durable Goods", Econometrica, vol. 39, 829844.

DEB, P. and TRIVEDI, P.K. (1997): "Demand for Medical Care by the Elderly in the United States: a Finite Mixture Approach”, Journal of Applied Econometrics, 12, 313-336.

DEB, P. and TRIVEDI, P.K. (2002): "The Structure of Demand for Health Care: Latent Class versus two-part models", Journal of Health Economics, 21, 601-625.

ENGLIN, J. and SHONKWILER (1995): "Estimating Social Welfare using Count Data Models: An Application to Long-run Recreation Demand under Conditions of Endogenous Stratification and Truncation", The Review of Economics and Statistics, 77, 104-112.

GOURIEROUX, C., MONFORT, A. and TROGNON, A. (1984a): "Pseudo Maximum Likelihood Methods: Theory”, Econometrica, 52, pp. 681-700. 
GOURIEROUX, C., MONFORT, A. and TROGNON, A. (1984b): "Pseudo Maximum Likelihood Methods: Applications to Poisson Models", Econometrica, 52, pp. 701-720.

GROGGER, J.T. and CARSON, R.T. (1991): "Models for Truncated Counts", Journal of Applied Econometrics, 6, 225-238.

GUIRAO, G., CÁCERES, J.J., CANO, V., HERNÁNDEZ, M., LÓPEZ, M.I., MARTÍN, F.J. and RODRÍGUEZ, M.C. (2001): El consumo de vino en Tenerife. Servicio Técnico de Desarrollo Rural y Pesquero, Cabildo Insular de Tenerife.

GUO, J. and TRIVEDI, P. (2002) "Flexible Parametric Models for Long-tailed Patent Count Distributions", Oxford Bulletin of Economics and Statistics, 64 (1), pp. 63-82.

GURMU, S. (1991): "Test for Detecting Overdispersion in the Positive Regression Model”, Journal of Business and Economics Statistics, 9, 215-222.

GURMU, S. and TRIVEDI, P.K. (1992): "Overdispersion Test for Truncated Poisson Regression Models", Journal of Econometrics, 54, 347-370.

GURMU, S. and TRIVEDI, P.K. (1996): "Excess of Zeros in Count Models for Recreational Trips", Journal of Business and Economics Statistics, 14, 469-477.

HAUSMAN, J.A., HALL, B.H. and GRILICHES, Z. (1984): "Econometric Models for Count Data with an Application to the Patents-R and D Relationship", Econometrica, 52, pp. 909-938.

JOHNSON, N.L. and KOTZ, S. (1969): Discrete Distributions. Boston. Houghton Mifflin.

LEDESMA, F.J., NAVARRO, M. and PÉREZ J.V. (2005): "Return to tourist destination. Is it reputation, after all?”, Applied Economics, 37, 2055-2065.

LEISCH, F. (2004): "FlexMix: A General Framework for Finite Mixture Models and Latent Class Regression in R”, Journal of Statistical Software, 11, 1-18.

LINDSAY, B.G. (1995): "Mixture Models: Theory, Geometry and Applications, NSF-CBMS Regional Conference Series in Probability and Statistics, vol. 5, IMSASA. Hayward, CA: Institute of Mathematical Statistics.

MULLAHY, J. (1986): "Specification and Testing of Some Modified Count Data Models", Journal of Econometrics, 33, 341-365.

MULLAHY, J. (1997): "Heterogeneity, Excess Zeros and the Structure of Count Data Models", Journal of Applied Econometrics, 12, pp. 337-350. 
NAYGA, R.M. (1996): "Sample selectivity models for away from home expenditures on wine and beer", Applied Economics, 28, 1421-1425.

SELVANATHAN, E.A. and SELVANATHAN, S. (2004): "Economic and demographic factors in Australian alcohol demand", Applied Economics, 36, 24052417.

SHAW, D. (1988): “On-site Samples Regression”, Journal of Econometrics, 37, 211 223.

SU S-J.B. and YEN S.T. (2000): "A censored system of cigarette and alcohol consumption", Applied Economics, 32, 729-737.

WANG, P., COCKBURN, I.M. and PUTERMAN, M.L. (1998): "Analysis of Patent Data -A Mixed Poisson Regression Model Approach", Journal of Business and Economics Statistics, 16 (1), 27-41.

WINKELMANN, R. and ZIMMERMANN, K.F. (1995): "Recent Development in Count Data Modelling: Theory and Applications", Journal of Economics Surveys, 9, $1-24$.

YEN, S.T. (1999): "Gaussian versus count-data hurdle models: cigarette consumption by women in the US", Applied Economics Letter, 6, 73-76. 


\section{Appendix}

Table 1. Variables included in the models

\begin{tabular}{|c|c|}
\hline $\begin{array}{l}\text { Frequency of wine consumption } \\
\text { FC }\end{array}$ & $\begin{array}{l}\text { Never }=0 \\
\text { Seldom }=1 \\
\text { Sometimes during a meal }=2 \\
\text { Often during a meal }=3 \\
\text { During every meal }=4\end{array}$ \\
\hline Sex & $\begin{array}{l}\text { Dummy variable reflecting gender: male }(=1) \text {, } \\
\text { female }(=2)\end{array}$ \\
\hline $\begin{array}{l}\text { Age: } \\
\text { E1 } \\
\text { E2 } \\
\text { E3 } \\
\text { E4 } \\
\text { E5 } \\
\text { E6 }\end{array}$ & $\begin{array}{l}\text { Dummy variable reflecting age: } \\
18-29 \\
30-39 \\
40-49 \\
50-59 \\
60-69 \\
\geq 70\end{array}$ \\
\hline $\begin{array}{c}\text { Residence: } \\
\text { A1 } \\
\text { A2 } \\
\text { A3 }\end{array}$ & $\begin{array}{l}\text { Dummy variable reflecting residential area: } \\
\text { Northern part of island } \\
\text { Southern part of island } \\
\text { Metropolitan area }\end{array}$ \\
\hline $\begin{array}{c}\text { Marital Status: } \\
\text { SF1 } \\
\text { SF2 } \\
\text { SF3 }\end{array}$ & $\begin{array}{l}\text { Dummy variable reflecting marital status } \\
\text { Married } \\
\text { Single } \\
\text { Widow/Separated } \\
\end{array}$ \\
\hline $\begin{array}{l}\text { Number of family members } \\
\text { MUF }\end{array}$ & $\begin{array}{l}\text { Variable reflecting number of family members in } \\
\text { family unit }(1,2,3, \ldots . .)\end{array}$ \\
\hline $\begin{array}{c}\text { Occupation } \\
\text { O1 } \\
\text { O2 } \\
\text { O3 } \\
\text { O4 } \\
\text { O5 } \\
\text { O6 } \\
\text { O7 }\end{array}$ & $\begin{array}{l}\text { Dummy variable reflecting occupation: } \\
\text { Employee } \\
\text { Civil Servant } \\
\text { Student } \\
\text { Housewife } \\
\text { Businessman } \\
\text { Professional } \\
\text { Other }\end{array}$ \\
\hline $\begin{array}{r}\text { Education } \\
\text { ED1 } \\
\text { ED2 } \\
\text { ED3 } \\
\text { ED4 } \\
\end{array}$ & $\begin{array}{l}\text { Dummy variable reflecting education: } \\
\text { Unfinished studies } \\
\text { Primary school student } \\
\text { Secondary school student } \\
\text { University student }\end{array}$ \\
\hline $\begin{array}{r}\text { Income } \\
\begin{array}{r}\text { I1 } \\
\text { I2 } \\
\text { I3 } \\
\text { I4 } \\
\text { I5 }\end{array}\end{array}$ & $\begin{array}{l}\text { Dummy variable reflecting monthly income level } \\
\text { (euros) } \\
<600 \\
600-1200 \\
1200-1800 \\
1800-2400 \\
>2400\end{array}$ \\
\hline
\end{tabular}


Table 2. Estimation results for entire sample $(\mathrm{N}=1172)$

\begin{tabular}{|c|c|c|c|c|c|c|c|c|c|c|c|c|c|c|}
\hline & & & & & & & & Hurdl & Model & & Finit & Mixture $M$ & del (Late & Class) \\
\hline \multirow{2}{*}{ Variables } & \multicolumn{2}{|c|}{ Poisson } & \multicolumn{2}{|c|}{ NEGBIN I } & \multicolumn{2}{|c|}{ NEGBIN II } & \multicolumn{2}{|c|}{ Logit } & \multicolumn{2}{|c|}{ P-Truncated } & \multicolumn{2}{|c|}{ Class I } & \multicolumn{2}{|c|}{ Class II } \\
\hline & Coeff. & p-value & Coeff. & p-value & Coeff. & p-value & Coeff. & p-value & Coeff. & p-value & Coef. & p-value & Coef. & p-value \\
\hline Constant & -0.947 & 0.000 & -0.946 & 0.000 & -0.947 & 0.000 & 1.268 & 0.005 & -0.303 & 0.184 & -0.832 & 0.000 & -2.088 & 0.020 \\
\hline $\mathrm{S} 2$ & -0.054 & 0.301 & -0.052 & 0.361 & -0.053 & 0.342 & -0.864 & 0.000 & -0.071 & 0.252 & -0.012 & 0.859 & -0.228 & 0.284 \\
\hline E1 & 0.646 & 0.000 & 0.646 & 0.001 & 0.647 & 0.000 & 0.960 & 0.026 & 0.502 & 0.008 & 0.592 & 0.002 & 1.149 & 0.058 \\
\hline E2 & 0.586 & 0.000 & 0.584 & 0.001 & 0.586 & 0.000 & 0.747 & 0.047 & 0.535 & 0.002 & 0.459 & 0.006 & 1.389 & 0.009 \\
\hline E3 & 0.425 & 0.001 & 0.423 & 0.032 & 0.426 & 0.002 & 0.537 & 0.125 & 0.473 & 0.005 & 0.234 & 0.159 & 1.254 & 0.007 \\
\hline E4 & 0.432 & 0.001 & 0.429 & 0.036 & 0.432 & 0.003 & 0.602 & 0.087 & 0.500 & 0.003 & 0.320 & 0.054 & 0.942 & 0.050 \\
\hline E5 & 0.166 & 0.182 & 0.163 & 0.248 & 0.166 & 0.228 & 0.369 & 0.229 & 0.225 & 0.177 & -0.031 & 0.854 & 0.858 & 0.052 \\
\hline A2 & 0.129 & 0.018 & 0.128 & 0.027 & 0.130 & 0.022 & 0.021 & 0.905 & 0.159 & 0.016 & 0.045 & 0.537 & 0.431 & 0.030 \\
\hline A3 & 0.220 & 0.000 & 0.220 & 0.001 & 0.220 & 0.001 & 0.128 & 0.511 & 0.166 & 0.017 & 0.233 & 0.002 & 0.240 & 0.340 \\
\hline SF2 & 0.002 & 0.979 & 0.001 & 0.928 & 0.002 & 0.979 & -1.138 & 0.000 & 0.093 & 0.290 & -0.047 & 0.606 & 0.198 & 0.496 \\
\hline SF3 & -0.086 & 0.292 & -0.085 & 0.348 & -0.085 & 0.336 & -0.540 & 0.028 & -0.057 & 0.567 & -0.072 & 0.481 & -0.068 & 0.818 \\
\hline MUF & 0.024 & 0.130 & 0.024 & 0.166 & 0.024 & 0.152 & 0.0005 & 0.993 & 0.030 & 0.108 & 0.008 & 0.719 & 0.078 & 0.248 \\
\hline $\mathrm{O} 2$ & -0.104 & 0.306 & -0.105 & 0.397 & -0.104 & 0.390 & 0.648 & 0.211 & -0.080 & 0.510 & -0.228 & 0.071 & 0.373 & 0.297 \\
\hline O3 & -0.053 & 0.538 & -0.054 & 0.568 & -0.053 & 0.566 & -0.682 & 0.017 & 0.052 & 0.604 & -0.138 & 0.213 & 0.295 & 0.432 \\
\hline O4 & 0.019 & 0.829 & 0.017 & 0.863 & 0.019 & 0.842 & -0.669 & 0.012 & 0.010 & 0.993 & -0.133 & 0.244 & 0.706 & 0.105 \\
\hline O5 & -0.0002 & 0.998 & -0.002 & 0.979 & -0.001 & 0.999 & -0.008 & 0.980 & 0.097 & 0.282 & -0.161 & 0.166 & 0.662 & 0.016 \\
\hline O6 & 0.074 & 0.406 & 0.072 & 0.423 & 0.074 & 0.400 & 0.759 & 0.127 & 0.111 & 0.281 & -0.089 & 0.435 & 0.958 & 0.015 \\
\hline O7 & -0.025 & 0.781 & -0.027 & 0.778 & -0.025 & 0.788 & -0.115 & 0.705 & -0.011 & 0.923 & -0.194 & 0.095 & 0.803 & 0.015 \\
\hline ED2 & 0.198 & 0.053 & 0.199 & 0.054 & 0.198 & 0.051 & 0.795 & 0.002 & 0.078 & 0.540 & 0.200 & 0.160 & 0.396 & 0.272 \\
\hline ED3 & 0.166 & 0.132 & 0.166 & 0.123 & 0.166 & 0.114 & 0.817 & 0.008 & -0.033 & 0.809 & 0.065 & 0.668 & 0.630 & 0.113 \\
\hline ED4 & 0.295 & 0.013 & 0.295 & 0.014 & 0.295 & 0.012 & 1.257 & 0.000 & 0.107 & 0.461 & 0.174 & 0.277 & 0.986 & 0.035 \\
\hline $\mathrm{I} 2$ & -0.102 & 0.228 & -0.102 & 0.239 & -0.102 & 0.231 & -0.580 & 0.024 & -0.014 & 0.891 & -0.062 & 0.601 & -0.263 & 0.371 \\
\hline $\mathrm{I} 3$ & -0.078 & 0.376 & -0.076 & 0.418 & -0.078 & 0.402 & -0.360 & 0.200 & -0.024 & 0.820 & 0.068 & 0.572 & -0.690 & 0.036 \\
\hline I4 & -0.132 & 0.189 & -0.129 & 0.231 & -0.132 & 0.215 & -0.306 & 0.363 & -0.132 & 0.277 & 0.118 & 0.394 & -1.297 & 0.004 \\
\hline I5 & -0.118 & 0.259 & -0.116 & 0.289 & -0.118 & 0.273 & 0.065 & 0.863 & -0.080 & 0.525 & 0.152 & 0.317 & -1.345 & 0.018 \\
\hline $\mathrm{FC}$ & 0.409 & 0.000 & 0.409 & 0.000 & 0.409 & 0.000 & & & 0.153 & 0.000 & 0.430 & 0.000 & 0.471 & 0.003 \\
\hline$\alpha$ & \multirow{2}{*}{\multicolumn{2}{|c|}{-1760.601}} & 0.019 & 0.683 & 0.0003 & 0.999 & & & \multirow{2}{*}{\multicolumn{2}{|c|}{-1338.331}} & \multirow{2}{*}{\multicolumn{4}{|c|}{-1740.718}} \\
\hline Ln L & & & -17 & .499 & -17 & .602 & \multicolumn{2}{|c|}{-565.248} & & & & & & \\
\hline
\end{tabular}

Editorial Office, Dept of Economics, Warwick University, Coventry CV4 7AL, UK 
Table 3. Estimation results for the consumer subsample $(\mathrm{N}=\mathbf{8 9 0})$

\begin{tabular}{|c|c|c|c|c|c|c|}
\hline & & & Finit & Mixture $M$ & lel (Late & Class) \\
\hline \multirow{2}{*}{ Variables } & \multicolumn{2}{|c|}{ Poisson } & \multicolumn{2}{|c|}{ Class I } & \multicolumn{2}{|c|}{ Class II } \\
\hline & Coeff. & p-value & Coeff. & p-value & Coeff. & p-value \\
\hline Constant & -0.924 & 0.000 & -0.969 & 0.017 & -0.903 & 0.257 \\
\hline S2 & -0.086 & 0.207 & -0.052 & 0.604 & -0.129 & 0.512 \\
\hline E1 & 0.598 & 0.004 & 0.425 & 0.174 & 1.371 & 0.158 \\
\hline E2 & 0.638 & 0.001 & 0.566 & 0.052 & 0.889 & 0.069 \\
\hline E3 & 0.564 & 0.002 & 0.349 & 0.229 & 0.874 & 0.058 \\
\hline E4 & 0.596 & 0.001 & 0.493 & 0.103 & 0.762 & 0.114 \\
\hline E5 & 0.265 & 0.144 & -0.079 & 0.786 & 0.827 & 0.057 \\
\hline $\mathrm{A} 2$ & 0.193 & 0.008 & -0.085 & 0.533 & 0.713 & 0.000 \\
\hline A3 & 0.201 & 0.009 & 0.287 & 0.013 & 0.063 & 0.796 \\
\hline SF2 & 0.113 & 0.242 & 0.256 & 0.078 & -0.607 & 0.199 \\
\hline SF3 & -0.068 & 0.534 & -0.016 & 0.922 & -0.285 & 0.345 \\
\hline MUF & 0.036 & 0.130 & -0.010 & 0.759 & 0.063 & 0.301 \\
\hline $\mathrm{O} 2$ & -0.097 & 0.468 & -0.209 & 0.248 & -0.038 & 0.932 \\
\hline $\mathrm{O} 3$ & -0.063 & 0.569 & -0.032 & 0.854 & 0.252 & 0.436 \\
\hline O4 & 0.003 & 0.978 & -0.229 & 0.219 & 0.455 & 0.192 \\
\hline O5 & 0.119 & 0.233 & -0.167 & 0.367 & 0.563 & 0.084 \\
\hline O6 & 0.136 & 0.233 & -0.082 & 0.657 & 0.352 & 0.261 \\
\hline $\mathrm{O} 7$ & -0.014 & 0.906 & -0.237 & 0.222 & 0.470 & 0.194 \\
\hline ED2 & 0.093 & 0.502 & 0.203 & 0.452 & -0.041 & 0.908 \\
\hline ED3 & -0.041 & 0.784 & -0.276 & 0.341 & 0.585 & 0.145 \\
\hline ED4 & 0.129 & 0.418 & 0.044 & 0.884 & 0.412 & 0.353 \\
\hline $\mathrm{I} 2$ & -0.018 & 0.874 & 0.295 & 0.127 & -0.696 & 0.018 \\
\hline $\mathrm{I} 3$ & -0.030 & 0.796 & 0.415 & 0.040 & -0.866 & 0.012 \\
\hline I4 & -0.161 & 0.228 & 0.332 & 0.155 & -0.988 & 0.012 \\
\hline I5 & -0.098 & 0.480 & 0.461 & 0.051 & -1.075 & 0.006 \\
\hline $\mathrm{FC}$ & 0.185 & 0.000 & 0.180 & 0.000 & 0.242 & 0.007 \\
\hline$\alpha$ & \multirow{2}{*}{\multicolumn{2}{|c|}{-1337.968}} & & & & \\
\hline Ln L & & & \multicolumn{4}{|c|}{-1305.646} \\
\hline
\end{tabular}

